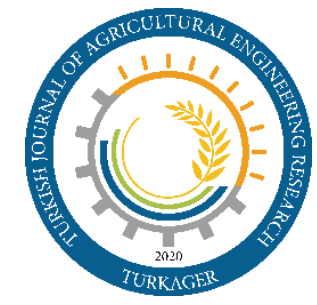

Turkish Journal of Agricultural Engineering Research

https://dergipark.org.tr/en/pub/turkager

https://doi.org/10.46592/turkager.2020.v01i02.013

Turk J Agr Eng Res

(TURKAGER)

e-ISSN: $2717-8420$

2020, 1(2): 390-403

Research Article

\title{
Yield Estimation of Winter Wheat in Pre-harvest Season by Satellite Imagery Based Regression Models
}

\author{
Ediz UNAL $\mathbf{a}^{*}$ Hakan YILDIZ ${ }^{\mathbb{I} a}$ Ali MERMER ${ }^{\mathbb{I}}$ Metin AYDOGDU \\ a Field Crops Central Research Institute, Shehit Cem Ersever Cad. No: 9-11, 06170, Yenimahalle, Ankara, TURKEY
}

(*): Corresponding author, edizunal@yahoo.com; Tel: +90-533-6226706, Fax: +90-312-3272893

\begin{abstract}
Early crop yield estimates could provide up-to-date information on supply, demand, stocks, and export availability through which governing bodies can make better agricultural management plans. This study aims to develop a yield model estimating pre-harvest winter wheat yield at both tillering and flowering stages using a multiple linear regression approach based on the relationship between actual yield and satellite derived crops' phenological parameters. Four crop parameters (NDVI, Cumulative NDVI, LAI and FPAR) were regressed in combination to find the best applicable model. Regression results showed that correlations for all models among the variables of the flowering period are higher than that of tillering $(0.63>0.53)$. The mean RMSE's of the observed vs predicted yields for tillering period was $645.9 \mathrm{~kg} \mathrm{ha}^{-1}$ and $574.5 \mathrm{~kg} \mathrm{ha}^{-1}$ for flowering period. The optimal developed model which consists of NDVI and CNDVI variables provided $76 \%$ and $79 \%$ of predicting accuracy 3 and 1.5 months before harvest respectively.
\end{abstract}

\section{RESEARCH ARTICLE}

Received: 09.07.2020

Accepted: 06.10.2020

\section{Keywords : \\ $>$ MODIS, \\ $>$ Remote sensing, \\ $>$ Vegetation index, \\ $>$ Wheat, \\ $>$ Yield prediction}

To cite: Unal E, Yildiz H, Mermer A, Aydogdu M (2020). Yield Estimation of Winter Wheat in Pre-harvest Season by Satellite Imagery Based Regression Models. Turkish Journal of Agricultural Engineering Research (TURKAGER), 1(2): 390-403.

https://doi.org/10.46592/turkager.2020.v01i02.013

\section{INTRODUCTION}

It's thought that wheat can feed the world in future. Recent records support this argument that wheat is one of the most two common cereals (with rice) available all over the world today since it is grown on more land area than the other commercial crops and continues to be the most important food source of the global population (Helene, 2012). It is therefore important to make an accurate and in time forecasts of wheat yield, through which policymakers do necessary actions for national food security and import-export decisions (Justice and Becker-Reshef, 2007).

As crop yield is considered to be one of the essential indicators for planning and monitoring of agricultural production, most of the wheat producing countries try to find and develop appropriate forecast methods. For this purpose, some techniques such as visual estimates, sample crop cut surveys, simulation models and statistical regression 
approaches have been used with some degrees of success (Doraiswamy et al., 2003). Among these, the most-used crop simulation models (CERES, WOFOST, CROPSYST and AQUACROP) seem appropriate for accurate forecasts because they integrate various environmental factors such as temperature, available water, wind, soil practices. But the main drawback of these complex models is that they mostly require several cropspecific inputs and are often limited by constraints that are not easy to measure without on-site field equipment. To overcome these limitations, easier and simpler methodologies, which use statistical regression approach based on the relationship between crop specific data captured via satellite and field data have been offered in the scientific literature (Dubey et al., 1994; Boken and Shaykewich, 2002; Wall et al., 2007).

Satellite imagery regressed yield estimation methods have been used for this purpose since the early 1970s (Colwell et al., 1977; Tucker et al., 1980; Wiegand et al., 1991; Serrano et al., 2000). The statistical regression models for yield forecasting generally depend on the experiential relations between field-measured yield (reference data) and reflectance based crop data. The basic assumption of this viewpoint is that yield relates with plant's spectral behaviors in the electromagnetic spectrum, which is responsive indicator of plants' development and live biomass to be assessed through spectral indices such as normalized difference vegetation indices (NDVI) leaf area index (LAI) and fractioned photosynthetic active radiation (FPAR) etc. (Tucker, 1979). In academic literature, many researches have been carried out in this field such as Fischer (1975) expressed that wheat yield was a function Tucker et al. (1980) found that wheat yield had a significant linear relationship with time-integrated NDVI in growing season. Pinter et al. (1981) found a similar result that wheat yield could be related to temporal cumulative NDVI during the growing period. Similarly, Doraiswamy et al. (2003) used several input variables derived from satellite imagery in a crop growth model to simulate wheat yields at county levels in North Dakota. Becker-Reshef et al. (2010) used official yield statistics and maximum NDVIs of the wheat growing period to develop a forecasting model for winter wheat production nearly two months before harvest in Ukraine. Even though all these statistical approaches have some disadvantages of being localized and non-extendible to vast areas, they are still preferred way due to simplicity and fewer input requirements.

This study aims firstly to develop a yield model estimating pre-harvest winter wheat yield at both tillering and flowering stages using multiple linear regression approach and then secondly to check the model's robustness and accuracy performance with root mean square error. Though this study reflects the results of a yield forecast model developed for a pilot area, the ultimate goal should be to find a simple and easy model at the national level providing information on yield and production supply for agricultural planning.

\section{MATERIAL and METHODS}

\section{Study area}

Central Anatolia is the main wheat-growing region of Turkey which makes approximately $30 \%$ of the total wheat areas (TUIK, 2011). Altinova TIGEM Farm locality, as a study area, lies in the central Anatolia homeland of Konya province, approximately $60 \mathrm{~km}$ North of Kadınhanı town (Figure 1). TIGEM farms are governmental establishments responsible for producing certified seeds of field crops 
(90\% of wheat) in vast areas of the country. Currently, there are 18 TIGEM farms which mostly grow cereal crops and some forage crops on their lands throughout the country (TIGEM, 2018).

Altinova TIGEM farm was selected as a study site because it has extensive parcels $(2 \times 2 \mathrm{~km})$, which allow working with moderate or low-resolution satellite imagery. In addition, it is also easy to obtain reliable parcel related yield records, total production, harvested area, etc. annually and historically with an official claiming. Continental climate prevails in the area with irregular rainfall which mostly occurs in winter and early spring within the year. The territory of Altinova TIGEM farm stretches almost 27 by $20 \mathrm{~km}$ in size with 76 main square parcels divided into 126 sub-parcels where cereals and forage crops are cultivated in rotation (Ünal and De Bie, 2017). In the farm area, winter wheat is mostly sown in October and crop germination starts in late November if climate conditions are suitable before entering winter dormancy. Vegetative development restarts in spring and reaches full maturity in summer before harvest season from early July to the first week of August.

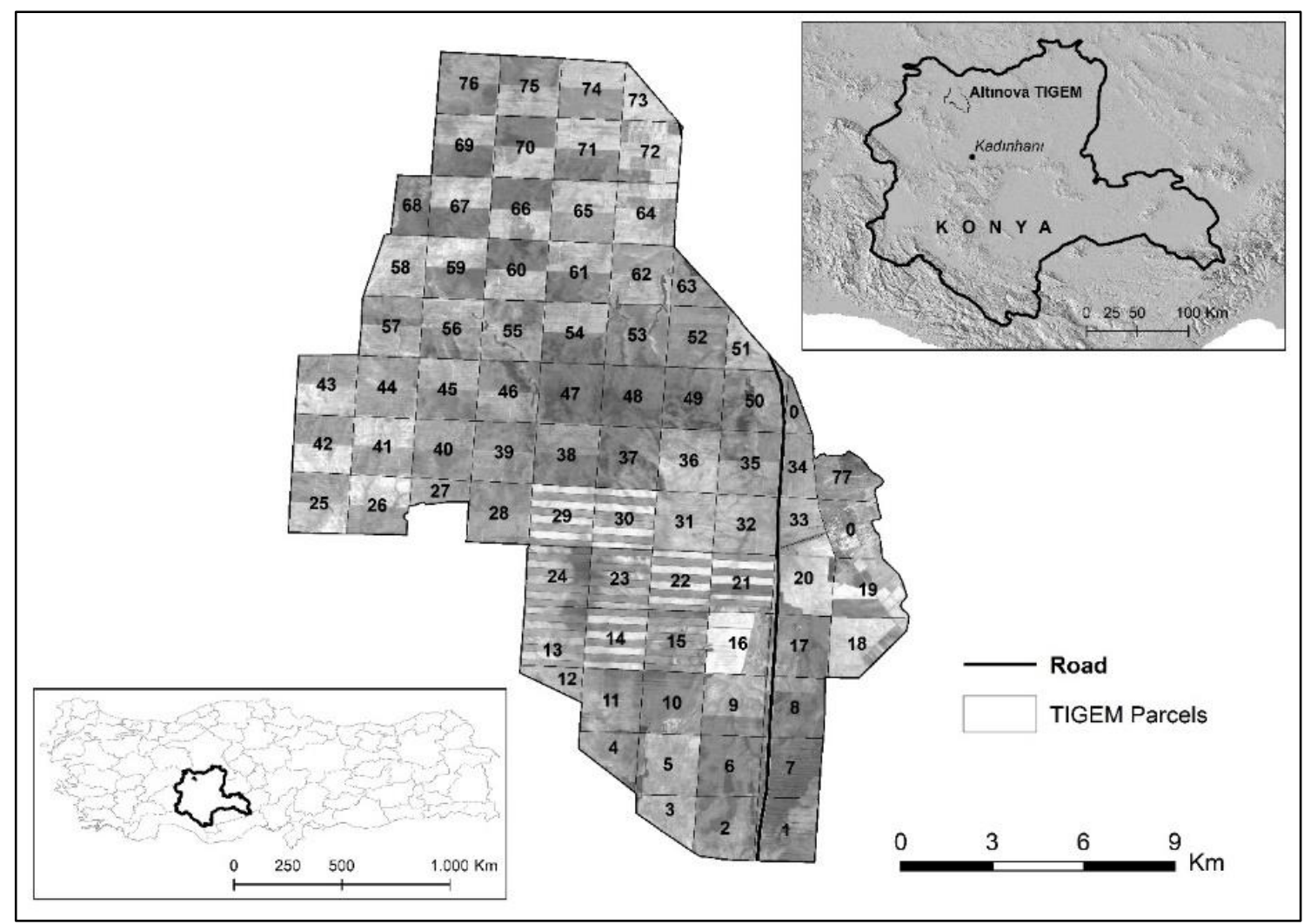

Figure 1. Study area and TIGEM Altınova Farm parcels.

\section{Data}

The study data includes satellite-derived data of wheat sown parcels and their actual yield records. Both data cover the six-year period (2008-2013) so as to construct a regression model of both tillering and flowering periods to forecast wheat yield prior to harvest. The yield models assess linear relationships between field and satellite data representing the variables as dependent and independent respectively. 


\section{Field Data}

Field data includes yield records of the parcels, which were collected from the measured grain mass weight of the harvested wheat crop by a combine harvester. A total of 438 yield records of the wheat sown parcels for the 6year period (2008-2013) were obtained from farm administration. While 282 of them were used in regression analysis as dependent variables to get yield models, remaining (156) called "Test Parcels" were used to check the performance of generated models using root mean squared errors (RMSE) values.

The use of RMSE is very common to measure model performance and considered a good general-purpose error metric for numerical predictions (Chai and Draxler, 2014). Field surveys were also conducted to check the overall condition of wheat parcels and to observe their vegetative development at the tillering and flowering stages. During the period of 2012-2015, a total of 24 field visit campaigns were organized. 21 of them were for vegetative monitoring and the remaining 3 visits were carried out just for the informative trip in harvest and germination stage. The parcels for field visits were selected based on the criteria that they should be accessible easily by vehicle and be distributed throughout the farm area (Figure 2). Surveys were done visually to see whether wheat crop entered tillering and flowering stages and also to observe the existing vegetative conditions.

Tillering and flowering periods were selected for the field campaigns because they are both pre-harvest time allowing yield forecasting in advance and are seem to be an important stage of crop growth (Acevedo et al., 2002; White and Edwards, 2008). The tillering period is important because it allows plants to take advantage of good growing conditions. Similarly, flowering stage provides maximum green canopy cover which reflects active biomass that can easily be captured by spectral measures such as NDVI and FPAR (Hanan et al., 1995). Although depending on the weather conditions and geographic locations, past experiences of consulted local farmers indicate that tillering generally coincides the date of approximately 3-months ahead of harvest, while flowering stage starts 1.5 months before harvest in the study area, which makes the first half of the April as "Tillering" and end of May as "Flowering". 


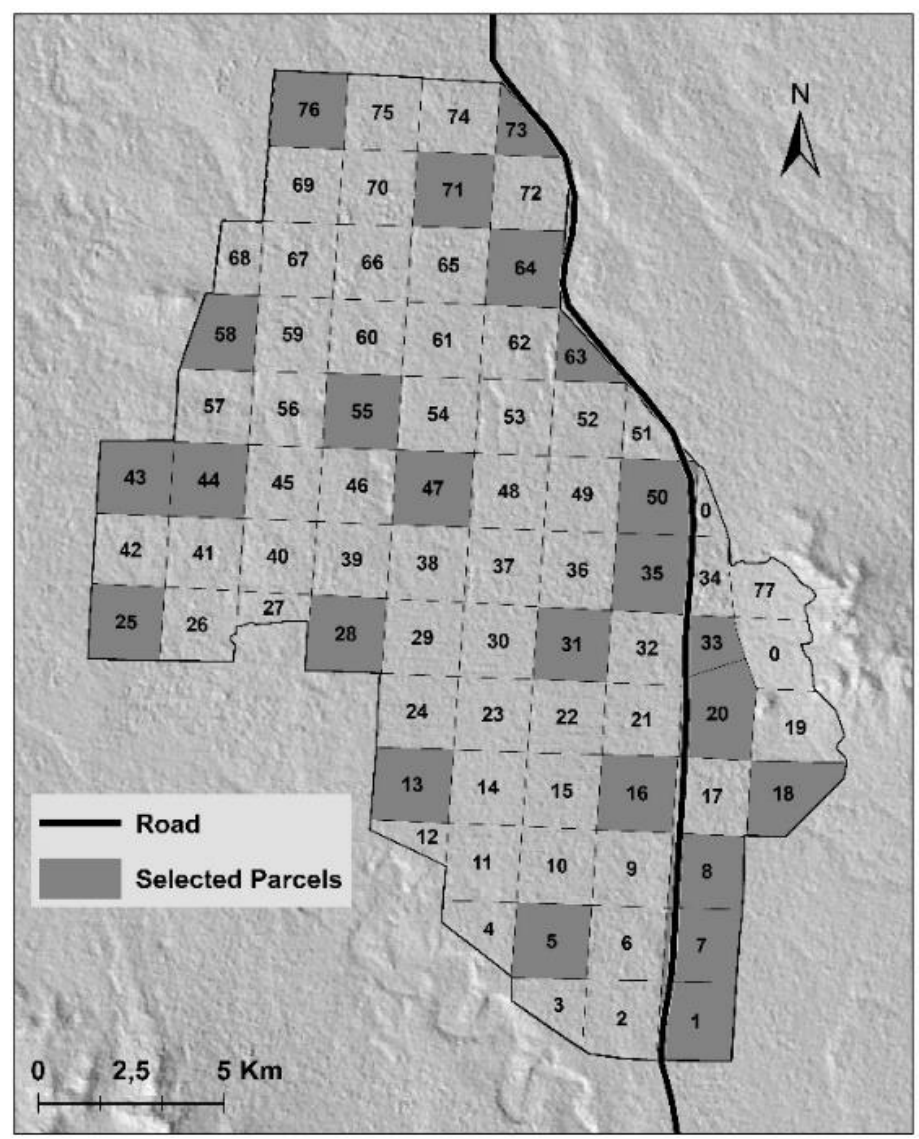

Figure 2. Study area and selected parcels

\section{Satellite and vector data}

Yield forecasting studies based on satellite data generally use parameters related to biophysical characteristics of crops such as vegetation index (VI), leaf area index (LAI) and fractioned photosynthetic active radiation (FPAR). These parameters are indicative of crop development, green biomass and eventually yield capacity, which were referred to in several scientific literature (Campbell, 1996; Prince and Goward, 1995; Huang et al., 2014). Remotely sensed data used in this study were normalized difference vegetation index (NDVI), temporal cumulative NDVI, leaf area index and fractioned photosynthetic active radiation which were all treated as independent variables in the regression models. NDVI, LAI and FPAR are as of grid data and ready-to-use products of the Moderate Resolution Imaging Spectrometer (MODIS) sensor and hereafter they're called MODIS products. All these raster data products were separately downloaded through the internet as a time series dataset matching "Tillering" and Flowering" periods from 2008 to 2013.

In this study, the seasonal maximum NDVI was treated as the main input parameter since it enabled a timely prediction of production approximately a month and a half prior to harvest (Becker et al., 2010). MODIS NDVI data were downloaded from the Global Agriculture Monitoring (GLAM) Project archive web site (GLAM, 2018). The GLAM data offers 16-day composite NDVI imagery produced from aerosol corrected surface reflectance data (Vermote et al., 2002). Cumulative NDVI's (CNDVI) of tillering and flowering stages were calculated by summing the NDVI dataset of starting from germination to end of the relevant stage. Tillering cumulative NDVI covers the February - March period, while the flowering stage of cumulative NDVI sums up all NDVI data from February to the end of May. LAI/FPAR data (MOD15A2 product) were 
retrieved from the online Data Pool, through the NASA Land Processes Distributed Active Archive Center (LP DAAC), USGS/Earth Resources Observation and Science (EROS) Center (USGS, 2018). The MODIS MOD15A2 LAI/FPAR product is produced globally at a $1 \mathrm{~km}$ resolution grid tiles from MODIS bands for all vegetated land surface and used to calculate surface photosynthesis, evapotranspiration, and net primary production.

Vector data consist of digitized parcel polygons as an ESRI shape file. A total of 125 polygons covers the whole TIGEM farm area. The vector dataset was used as a zone to retrieve the cell values of independent variables in raster format.

\section{Methodology}

The methodology of this study was based on the approach that satellite-derived data of crops' parameters have a relationship with the actual yields, which made available to develop a yield estimation model with multiple linear regression. Multiple regression analysis is used to see if there is a statistically significant relationship between sets of variables and to find trends in those sets of data. This relationship here is such explained that crop yield is dependent upon the at least two crop parameters or more which were given here as mean NDVI, cumulative NDVI, LAI and FPAR. The resulting yield model/models calculate(s) the wheat yield as a function of these parameters in combination aiming to get the most accurate one. The following equation (Eq. 1) is given to represent a yield model with 4 variables as an example.

Yield $=\mathrm{f}(\mathrm{NDVI}, \mathrm{CNDVI}, \mathrm{LAI}$, FPAR)

The relationship between the parameters is linear and represented in multiple regression yield model as follow (Eq. 2);

$y=\alpha+\beta N D V I+\eta C N D V I+\varepsilon L A I+\gamma F P A R$

Where, $\mathrm{y}$ is the wheat yield as dependent variable. $\alpha, B, \eta, \varepsilon$ and $\mathrm{Y}$ are coefficients, NDVI, CNDVI, LAI and FPAR are the input crop parameters representing independent variables.

The values of crop parameters required for the regression model were retrieved through GIS analysis (ARCGIS-ESRI Software) with a zonal statistics tool, which allows us to calculate statistics on the values of raster data within the zones of vector dataset. The vector dataset represents parcels borders as polygon features. The zonal tool calculates the mean value of all pixels within each zone (parcel polygon) of the specified raster dataset (NDVI, CNDVI, LAI and FPAR) and produces an attribute table where all parcels are listed with a mean value of relevant raster data. Zonal statistics were applied for all MODIS products at both tillering and the flowering phase during 6 year period and parcel-based results were exported to the statistical datasheet as independent variables. The parcels' yield records were also added to this resultant sheet as a dependent variable ready for multiple regression analysis. The graphical representation of the methodology was given in Figure 3. 


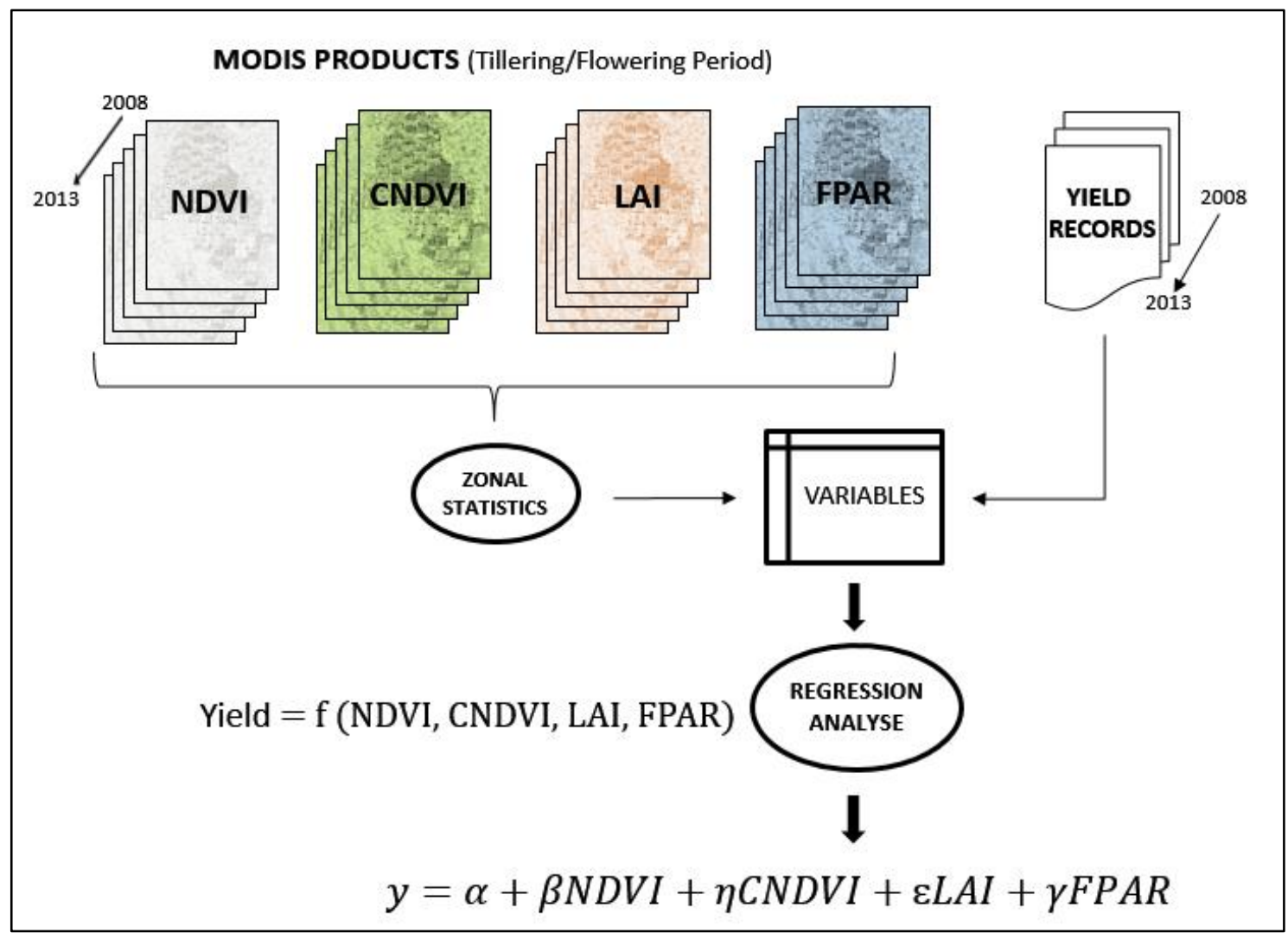

Figure 3. Methodology of the study

Since the final aim is to find the best yield model which could provide more accurate results, series of independent variables in the regression were used in combination keeping NDVI and CNDVI as two primary predictors. So four different yield models below were developed based on the number of independent variables.

Model 1: (NDVI, CNDVI, LAI and FPAR),

Model 2: (NDVI, CNDVI and FPAR),

Model 3: (NDVI, CNDVI and LAI),

Model 4: (NDVI and $C N D V I)$

Used variables and coefficients in the models are given in Figure 4.

The four regression models were run for 6 years of data for both tillering and flowering stages to obtain yield equations. A total of 282 data points for 6 year period was used in the analysis to develop models to forecast the yields of Test Parcels (TP). The predicted yields and the accuracy of the models' prediction were compared to actual yields and assessed using the root mean square error (RMSE) expressed in units of the measured data ( $\left.\mathrm{kg} \mathrm{ha}^{-1}\right)$. The RMSE gives the weighted variations in errors (residual) between the predicted and observed values and was calculated as follows (Eq. 3);

$$
R M S E=\sqrt{\frac{1}{n} \sum_{i=1}^{n}\left(P_{i}-O_{i}\right)^{2}}
$$

Where $\mathrm{n}$ is the number of observations, $\mathrm{Pi}$ is the predicted yield and $\mathrm{Oi}$ is the measured yield. 


\section{RESULTS and DISCUSSION}

To evaluate the models, predicted versus observed values were regressed and their coefficients of determination were compared. Four different yield models generated based on the number of used explanatory variables were separately tested with scatter plots of observed vs. predicted yields and the resulting models produced following yield equations (Figure 4). The results show that the highest correlations were found in Model 1 and Model $3\left(r^{2}=0.539\right)$ while the lowest one was seen in Model $4\left(r^{2}=0.535\right)$ for the tillering period. Model 1 and Model 2 provided slightly higher correlations $\left(r^{2}=0.635\right)$ than Model 3 and Model 4 did with the $\mathrm{R}^{2}$ values of 0.633 and 0.632 respectively for the flowering period.

Regression results showed that correlations between the dependent variable and independent variables for the flowering period are higher than that of the tillering period (0.63>0.53), because of the full canopy cover occurred in the flowering stage, which was also validated by field survey observations conducted at the first week of March and the end of May (Figure 5). Canopy cover is considered to be an important aspect that has a strong relationship, at some level (until $80 \%$ green coverage), with crops' phenologic metrics such as NDVI, LAI and FPAR and hence is the indication of yield according to various scientific literature (Ahlrichs and Bauer, 1983; Zhao, 2003; Jiang, 2006; Ren, 2008).

In order to test the predictive performance of the developed models for both stages, predicted yields of 156 test parcels through 2008-2013 were compared to observed yields and evaluated with RMSE values (Table 1). The mean RMSE's of the observed vs predicted yields for the tillering period was $645.9 \mathrm{~kg} \mathrm{ha}^{-1}$ equivalent to $23.53 \%$ error and for the flowering period $574.5 \mathrm{~kg} \mathrm{ha}^{-1}$ with an error of $20.93 \%$. This underlines that four models' yield estimation performance is higher in flowering than in the tillering period because of the steadily increasing NDVI values which affect wheat yield to rise accordingly. This is consistent with the findings of Babar et al. (2006), Aparicio et al. (2000) and Royo et al. (2003) that there was a strong positive relationship between yield and NDVI.

All models produced similar performance results for both stages. RMSE values of models' results for tillering and flowering stage are very close to each other with very low standard deviations of 0.14 and 0.10 respectively. These results suggest that it's rational to use a simple model requiring fewer inputs with an acceptable estimation accuracy in comparison with others. Model 4 consisting of NDVI and CNDVI variables seems to be an appropriate yield estimation model in these conditions providing $76 \%$ of accuracy for the tillering period and $79 \%$ for the flowering period. 


\section{TILLERING}

FLOWERING

Model 1 variables; NDVI, CNDVI, LAI, FPAR
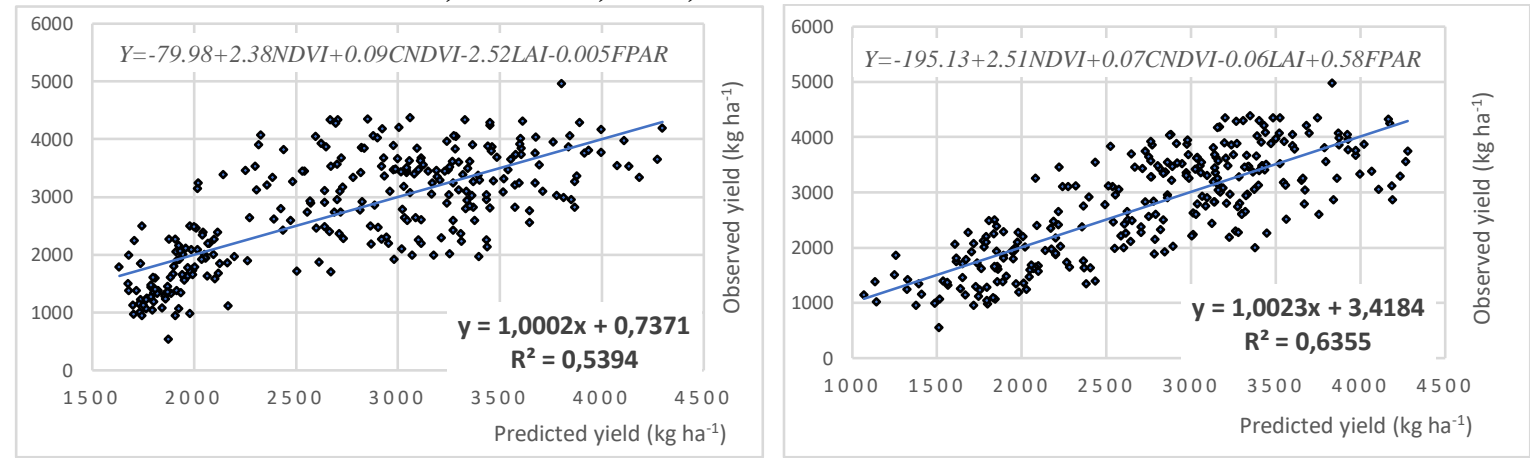

Model 2 variables; NDVI, CNDVI, FPAR
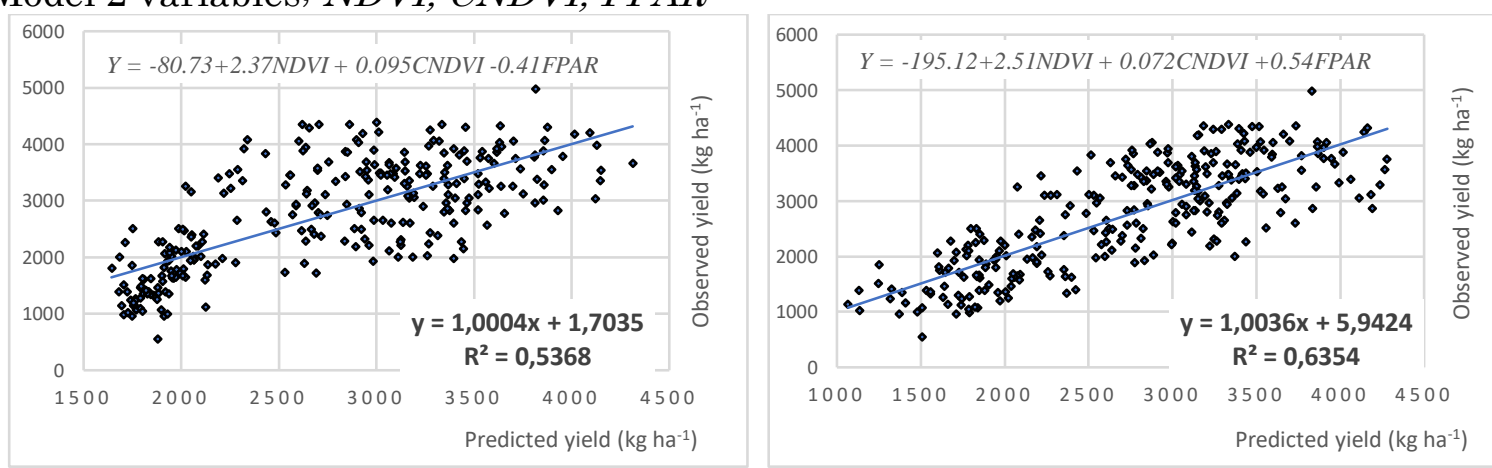

Model 3 variables; NDVI, CNDVI, LAI
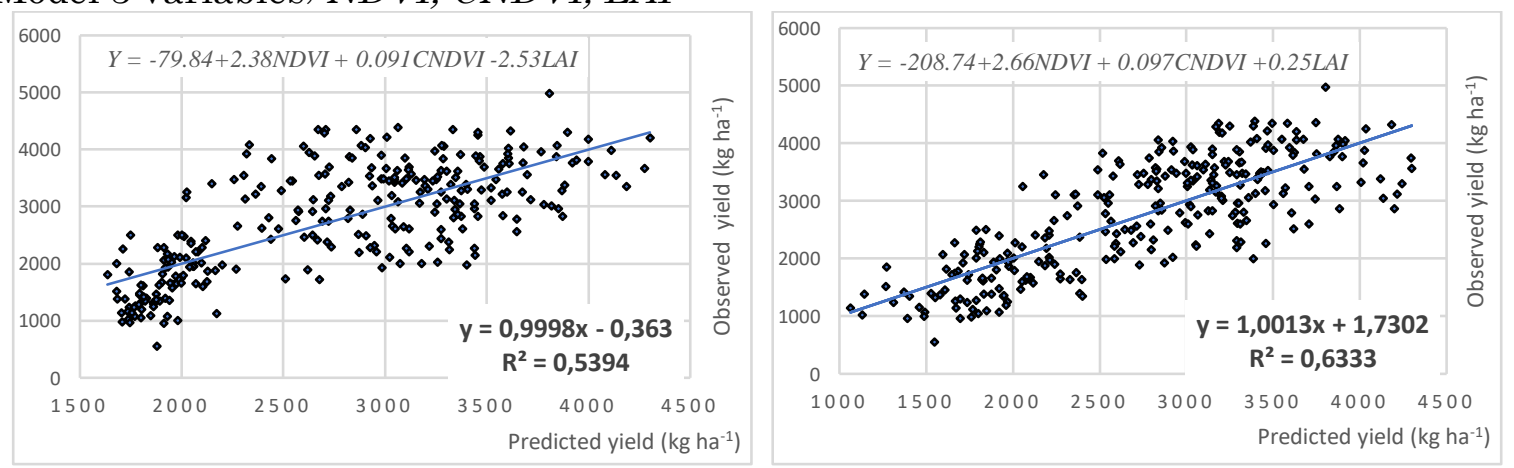

Model 4 variables; $N D V I, C N D V I$
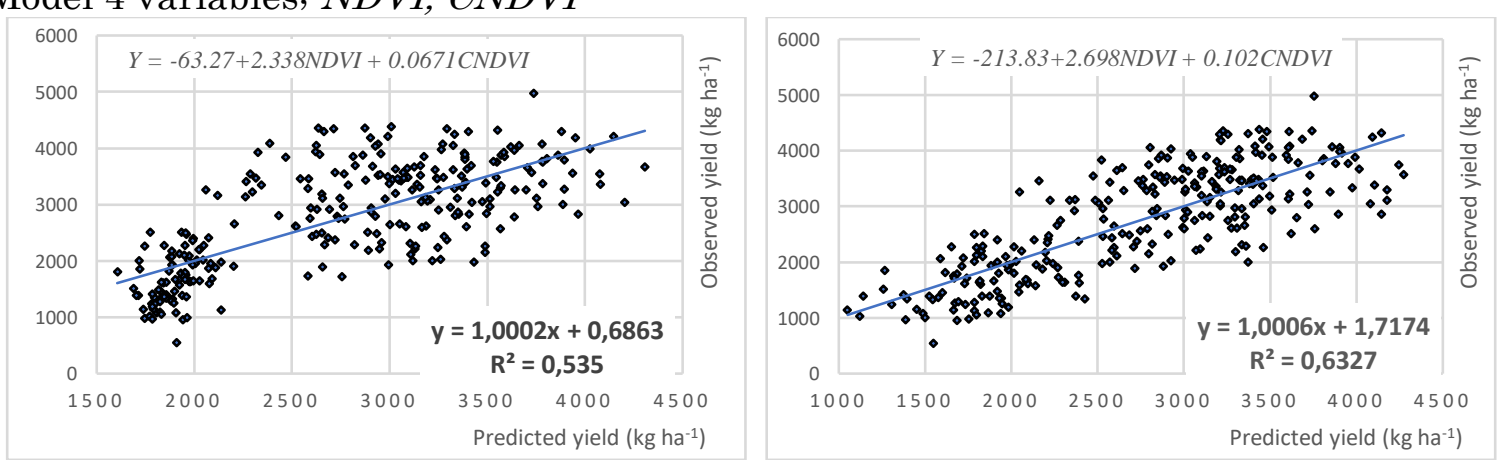

Figure 4. Yield models equations and correlations between predicted and observed yields 
Tillering

Flowering

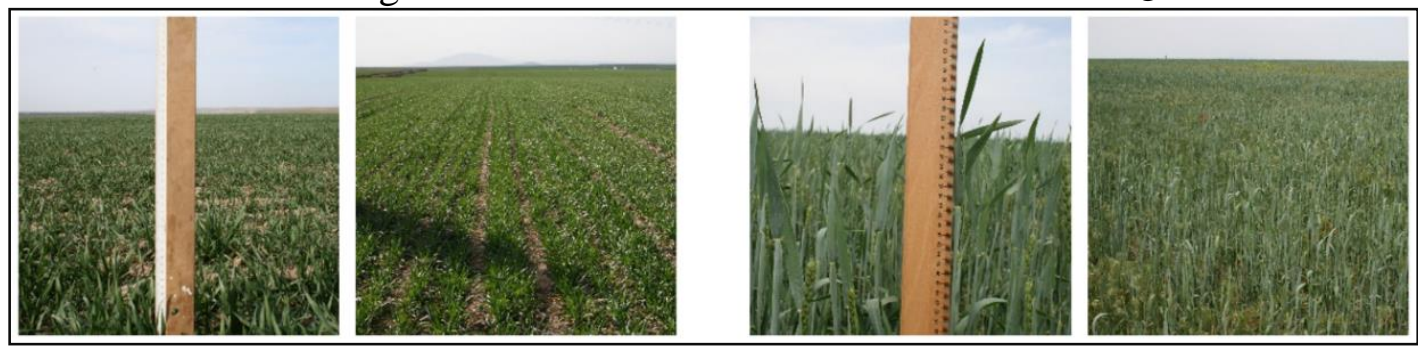

Figure 5. Pictures from field surveys at tillering and flowering periods

Table 1. Yield models' performances in terms of RMSE at growing period

\begin{tabular}{|c|c|c|c|c|c|}
\hline \multirow{3}{*}{ Models } & \multirow{3}{*}{$\begin{array}{l}\text { Explanatory } \\
\text { Variables }\end{array}$} & \multicolumn{4}{|c|}{ Growing Stages } \\
\hline & & \multicolumn{2}{|c|}{ Tillering } & \multicolumn{2}{|c|}{ Flowering } \\
\hline & & RMSE (kg ha-1) & RMSE \% & RMSE (kg ha-1) & RMSE\% \\
\hline Model 1 & $\begin{array}{l}\text { NDVI } \\
\text { CNDVI } \\
\text { LAI } \\
\text { FPAR }\end{array}$ & 644.71 & 23.49 & 573.68 & 20.90 \\
\hline Model 2 & $\begin{array}{l}\text { NDVI } \\
\text { CNDVI } \\
\text { LAI }\end{array}$ & 644.80 & 23.49 & 575.29 & 20.96 \\
\hline Model 3 & $\begin{array}{l}\text { NDVI } \\
\text { CNDVI } \\
\text { FPAR }\end{array}$ & 646.52 & 23.55 & 573.72 & 20.90 \\
\hline Model 4 & $\begin{array}{l}\text { NDVI } \\
\text { CNDVI }\end{array}$ & 647.85 & 23.60 & 575.70 & 20.97 \\
\hline Mean & & 645.91 & 23.53 & 574.51 & 20.93 \\
\hline Std. dev. & & 0.14 & 0.14 & 0.10 & 0.03 \\
\hline
\end{tabular}

Notably, the models predict the yields better in the flowering stage than they do in the tillering period producing approximately a 3\% accuracy increase in RMSE. Figure 6 shows the predicted yields at the tillering and flowering stages with their difference values from the measured yields as an absolute percentage value (deviation). It's clear that the number of parcels which have high deviation values at tillering period decreased in flowering period meaning the models provide better accuracy when crops enter flowering stage approximately 1.5 months prior to harvest. This situation does not offer satisfactory advantages for authorities because predictions need to be available as early in the growing season as possible. Yet, the local farmers or mid-size farms could benefit from it to estimate possible incomes-expenses and to make arrangements for farming. 

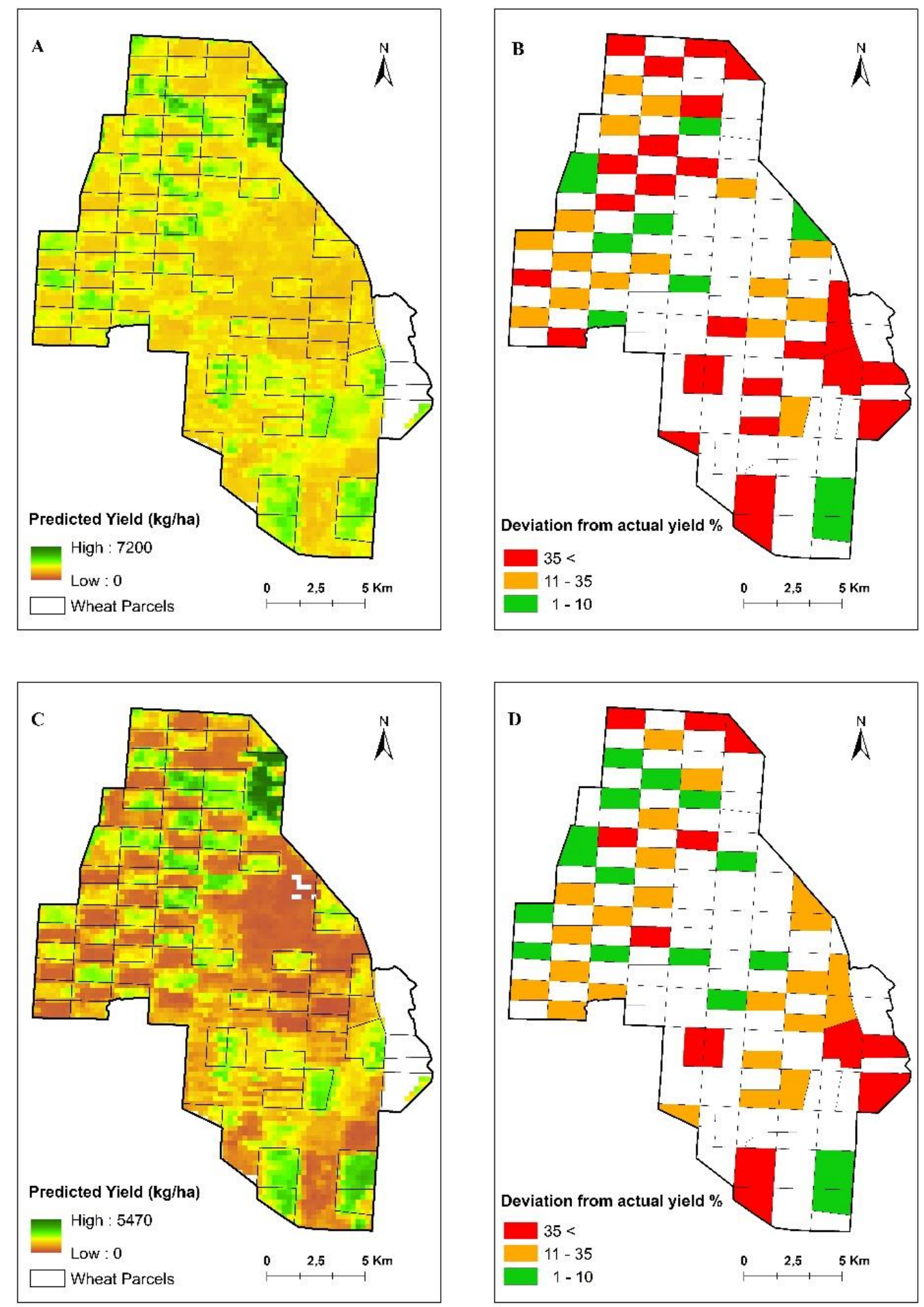

Figure 6. Predicted yields and deviations from actual yield. Model 4 (NDVI-CNDVI) predicted the yields of wheat parcels of TIGEM Farm in 2014 growing season before harvest time at tillering $(\mathrm{A})$ and then flowering stage $(\mathrm{C})$. Deviations were calculated as an absolute value from the difference between actual yields and predicted ones at both tillering (B) and flowering (D) stages. 


\section{CONCLUSION}

This study aimed to develop a yield model estimating pre-harvest winter wheat yield at both tillering and flowering stages using multiple linear regression approach. Yield models were based on the relationship between satellite data derived independent variables (NDVI, Cumulative NDVI, LAI and FPAR) and observed yields at field level. The predictive performance of the developed four different models was tested and evaluated with actual yields and RMSE. According to the results; all models could predict the yield with approximately $76 \%$ accuracy at the tillering period and $79 \%$ accuracy at the flowering period which corresponds to 3 months and 1 month before harvest time respectively. Though prediction accuracy is higher for the flowering period, it's not advisable to make a prediction in this period because harvesting time is close and there isn't be enough time for actions such as crop insurance, cash-flow budgeting, planning harvest and storage requirements.

Even though all models give more or less the same performance results, the model consisting of NDVI and temporal cumulative NDVI variables was the best one in terms of simplicity and easy applicability. Estimation accuracy may not be considered as sufficient, but yet predicted yield figures could give valuable information especially 3 months before harvesting for governing bodies to make agricultural management plans on supply and demand for the crop. This study showed that satellite based yield models provide an easy crop yield estimations with low cost and time saving especially for large areas. Producing the most ideal forecasting models based on climatic and environmental conditions and including additional variables for different product types should be one of the main objectives in subsequent studies.

\section{DECLARATION OF COMPETING INTEREST}

The authors of this research article declare that they have no conflict of interest.

\section{CREDIT AUTHORSHIP CONTRIBUTION STATEMENT}

The authors of this research article declare that they contributed to conduct the research project herewith leading the writing of this manuscript with following personel tasks;

Ediz Unal: Conducting project, field survey and work, data obtain and analysis, writing project report and base manuscript

Hakan Yildiz: Field survey and work, GIS analysis and mapping tasks, writing manuscrip sections

Ali Mermer: Field survey and work, writing project report, manuscript sections and redaction

Metin Aydogdu: Field survey and work, writing project report and manuscript redaction

\section{ACKNOWLEDGEMENTS}

This research study was supported by the General Directorate of Agricultural Research and Policies through Agricultural Research Projects (Project No: TAGEM/TBAD/12 A12/PO7/01). We express our gratitude to all project staff for contributing the field studies and office work. 


\section{REFERENCES}

Acevedo E, Silva P and Silva H (2002). Wheat growth and physiology. FAO Plant Production and Protection Series (FAO), 0259-2525, no. 30, Food and Agriculture Organization of the United Nations, Rome.

Ahlrichs JS and Bauer ME (1983). Relation of agronomic and multispectral reflectance characteristics of spring wheat canopies. Agronomy Journal, 75 (6): 987-993.

Aparicio N, Villegas D, Casadesus J, Araus JL and Royo C (2000). Spectral vegetation indices as nondestructive tools for determining durum wheat yield. Agronomy Journal, 92: 83-91.

Babar MA, Reynolds MP, Van Ginkel M, Klatt AR, Raun WR and Stone ML (2006). Spectral reflectance indices as a potential indirect selection criteria for wheat yield under irrigation. Crop Science, 46: 578588.

Becker RI, Vermote E, Lindeman M and Justice C (2010). A generalized regression-based model for forecasting winter wheat yields in Kansas and Ukraine using MODIS data. Remote Sensing of Environment, 114: 1312-1323.

Boken VK and Shaykewich CF (2002). Improving an operational wheat yield model using phenological phase-based Normalized Difference Vegetation Index. International Journal of Remote Sensing, 23: 4155-4168.

Campbell JB (1996). Introduction to Remote Sensing. Guilford Press, New York, NY, USA.

Chai T and Draxler RR (2014). Root mean square error (RMSE) or mean absolute error (MAE) - Arguments against avoiding RMSE in the literature. Geoscientific Model Development, 7 (3): 1247-1250.

Coldwell JE, Rice DP and Nalepka RF (1977). Wheat yield forecasts using Landsat data. Proceedings of 11th International Symposium on Remote Sensing of Environment. Ann Arbor MI, pp. 1245-1254.

Dubey RP, Ajwani N, Kalubarme MH, Sridhar VN, Navalgund RR, Mahey RK, Sidhu SS, Jhorar OP, Cheema SS and NA RANG RS (1994). Preharvest wheat yield and production estimation for the Punjab, India. International Journal of Remote Sensing, 15: 2137-2144.

Doraiswamy PC, Moulin S, Cook PW and Stern A (2003). Crop yield assessment from remote sensing. Photogrammetric Engineering and Remote Sensing, 69: 665-674.

Fischer RA (1975). Yield potential in dwarf spring wheat and the effect of shading. Crop Science 15: 607613.

GLAM (2018). Global agricultural monitoring project. [online]. Website (http://pekko.geog.umd.edu/usda/test). (18.03.2019).

Hanan NP, Prince S and Begue A (1995). Estimation of absorbed photosynthetically active radiation and vegetation net production efficiency using satellite data. Agriculture for Meteorology, 76: 259-276.

Helene L (2012). GCARD2. Breakout session P1.1 National Food Security - Speaker Brief - The Wheat Initiative - an International Research Initiative for Wheat Improvement. Second Global Conference on Agricultural Research for Development, Uruguay.

Huang J, Wang H, Dai Q and Han D (2014). Analysis of NDVI data for crop identification and yield estimation. Selected Topics in Applied Earth Observations and Remote Sensing IEEE Journal, 7 (11): 4374-4384.

Jiang Z, Huete RA, Chen J, Chen Y, Li J, Yan G and Zhang X (2006). Analysis of NDVI and scaled difference vegetation index retrievals of vegetation fraction. Remote Sensing of Environment, 101: 366-378.

Justice CO and Becker-Reshef I (2007). Developing a strategy for global agricultural monitoring in the framework of Group on Earth Observations Report. FAO, Rome, Italy.

Pinter PJ, Jackson RD, Disco SB and Reginato RJ (1981). Multidate spectral reflectances as predictors of yield in water stressed wheat and barley. International Journal of Remote Sensing, 2: 43-48.

Prince SD and Goward SN (1995). Global primary production: a remote sensing approach. Journal of Biography 22: 815-835.

Ren J, Chen Z, Zhou Q and Tang H (2008). Regional yield estimation for winter wheat with MODIS-NDVI data in Shandong. China International Journal of Applied Earth Observation and Geoinformation, 10: 403-413.

Royo C, Aparicio N, Villegas D, Casadesus J, Monneveux P and Araus JL (2003). Usefulness of spectral reflectance indices as durum wheat yield predictors under contrasting Mediterranean conditions. International Journal of Remote Sensing, 24: 4403-4419.

Serrano L, Filella I and Penuelas J (2000). Remote sensing of biomass and yield of winter wheat under different nitrogen supplies. Crop Science, 40: 723-731.

TIGEM (2018). General Directorate of Agricultural Enterprises. [online]. Website http://www.tigem.gov.tr. (22.04.2019). 
Tucker CJ (1979). Red and photographic infrared linear combination for monitoring vegetation. Remote Sensing of Environment, 8(2): 127-150.

Tucker CJ, Elgin JH and McMurtrey JE (1980). Relationship of spectral data to grain yield variation. Photogrammetric Engineering and Remote Sensing, 46(5): 657-666.

TUIK (2012). The Summary of Agricultural Statistics. Turkish Statistical Institute. Ankara, Turkey.

Ünal E and Debie CAJM (2017). Mapping wheat growing areas of Turkey by integrating multi-temporal NDVI data and official crop statistics. Journal of Field Crops Central Research Institute, 26 (1): 11-23.

USGS (2018). USGS Earth Resources Observation and Science (EROS) Center. [online]. Website https://earthexplorer.usgs.gov/ (05.03.2019).

Vermote EF, El Saleous NZ and Justice CO (2002). Atmospheric correction of MODIS data in the visible to middle infrared: first results. Remote Sensing of Environment, 83: 97-111.

Wall L, Larocque D and Leger PM (2007). The early explanatory power of NDVI in crop yield modeling. International Journal of Remote Sensing, 29: 2211-2225.

Wiegand CL, Richardson AJ, Escobar DE and Gerbermann AH (1991). Vegetation indices in crop assessment. Remote Sensing of Environment, 35: 105-119.

White J and Edwards J (2008). Wheat growth and development. NSW Department of Primary Industries, Orange, Australia.

Zhao YS (2003). Methods and Theories of Remote Sensing Application and Analysis. Science Press. Beijing, China. 